\title{
Um novo paradigma para a aprendizagem da complexidade das relações água/solo/planta/atmosfera
}

\section{A new paradigm for the learning process about the complexity of the relations water/soil/plant/atmosphere}

\author{
Ricardo Serra Borsatto ${ }^{1}$; Nilce Nazareno da Fonte ${ }^{2}$; Celina Wisniewski²; \\ Wellington Cesar Adão ${ }^{3}$; Michelle Melissa Althaus Ottmann ${ }^{4 *}$
}

\section{Resumo}

\begin{abstract}
Este ensaio compartilha as dificuldades e os caminhos percorridos, dentro de uma disciplina de pósgraduação, quando utilizado um novo paradigma para o ensino-aprendizagem das diversas relações naturais existentes dentro de ecossistemas. Para tanto no decorrer deste ensaio é realizada uma fundamentação teórica que visa evidenciar as carências do paradigma cartesiano na compreensão de ecossistemas naturais, ao final são propostos novos caminhos para este ensino-aprendizagem, os quais sugerem uma visão e abordagem mais holística e sistêmica acerca dos ecossistemas naturais, de forma a demonstrar a complexidade das infinitas relações presentes nos mesmos. Por meio de leituras e discussões de textos escritos por autores que alertam para a necessidade de haver uma nova maneira de se entender os ecossistemas naturais e ainda por meio de uma visita a um ecossistema particular na Ilha do Mel, PR, os discentes realizaram trocas de percepções, aonde foi evidenciada a diferença de percepções de um mesmo ecossistema, e apesar disto todos estavam à sua maneira representando a realidade. Foi possível então, observar que os alunos despertaram para a importância e necessidade de haver uma nova abordagem não só de ecossistemas naturais, mas também do próprio mundo urbano no qual vivemos. Palavras-chave: Epistemologia ambiental, educação
\end{abstract}

\begin{abstract}
This article shares the undertaken difficulties and approaches when a new paradigm is used for the teach-learning relations existing inside natural ecosystems. For this, throughout this essay, a theoretical justification is accomplished that aims to evidence the insufficiency of the Cartesian paradigm on understanding the natural ecosystem. New approaches are pointed out for this teach-learning, which are suggested a new vision and approach, much more holistic and systemic about the natural ecosystems, by the way to demonstrate the complexity of the infinities relations between them. Through lectures and discussions of texts, which were written by authors that show the necessity of having a new way to understand the naturals ecosystems and with a visit to an ecosystem in Ilha do Mel, PR, Brazil, the students realized changings of perceptions, and it was evidenced the difference between perceptions about the same ecosystem although each one represented the reality. It was possible to observe that all the students realized the importance and necessity to have a new approach, not only about the naturals ecosystems, but also about our urban world.
\end{abstract}

Key words: Environmental epistemology, education

1 Engenheiro Agrônomo, Mestre em Agronomia, Doutorando em Engenharia Agrícola, Universidade Estadual de Campinas, UNICAMP. E-mail: rsborsat@ig.com.br

2 Professoras Dras. do Programa de Pós-Gradução em Agronomia da Universidade Federal do Paraná. E-mail: cewisni@ufpr.br; nilce@ufpr.br

3 Eng. Agrônomo, Mestrando em Ciências do Solo, Depto. de Solos, Universidade Federal do Paraná, UFPR. E-mail: wcadao@terra.com.br

${ }^{4}$ Engenheira Florestal, Mestre pelo Programa de Pós-Graduação em Agronomia, UFPR. E-mail: michellealthaus@ hotmail.com

* Autor para correspondência 


\section{Introdução}

O conhecimento científico é uma conquista recente da humanidade, surgiu no século XVII com a revolução galileana, porém nestes seus trezentos anos de existência evoluiu de forma espantosa nas diversas áreas do conhecimento, seja na física, na biologia, na psicologia, na sociologia; por meio de métodos de verificação empírica e lógica. O conhecimento científico, utilizando-se da razão, rejeita os mitos, trazendo luz ao nosso saber (ARANHA; MARTINS, 1993).

Mas apesar de toda esta evolução, o erro, a ignorância, a cegueira, a desigualdade social, as guerras, a destruição ambiental, a ameaça nuclear, e um número infinito de problemas progridem simultaneamente aos nossos conhecimentos (MORIN, 2001b). Pois como explicitam Aranha e Martins (1993), embutido no ideal cientificista está o "mito do progresso" que é utilizado para justificar quaisquer ações humanas. Porém, esta visão meramente tecnicista tem gerado consequiências indesejáveis: as construções urbanas tornaram a vida humana cada vez mais solitária; as fábricas poluem o ar que respiramos; a especulação imobiliária e a agricultura destroem a natureza; a modernização da agricultura compacta os solos, polui os rios e exclui os pequenos produtores, ou seja, a opulência não expulsa a miséria, mas convive com ela lado a lado.

Concordamos com Morin (2001a), o preconizador da teoria da complexidade, quando este coloca que vivemos no "paradigma da simplificação" onde imperam os princípios de disjunção, de redução e de abstração. O mesmo autor (MORIN, 2001b) considera necessária uma tomada de consciência radical e nos alerta que: a- A causa profunda do erro está no modo como organizamos o nosso saber em sistemas de idéias (teorias, ideologias); b- Existe uma nova ignorância ligada ao desenvolvimento da própria ciência; c- Existe uma nova cegueira ligada ao uso degradado da razão; d- O progresso cego e descontrolado do conhecimento científico é que está causando as mais graves ameaças em que a humanidade incorre (armas nucleares, manipulações de todas as espécies, desequilíbrio ecológico, etc.).
A universidade, no decorrer do século XX, seguiu uma trajetória crescentemente especializante, mas por fim, no final de século XX e início do XXI, começou a despertar para uma necessária revisão de sua trajetória, buscando encontrar novas respostas às perguntas que o mundo real apresenta (BURSZTYN, 2004).

É dentro desta moldura que a disciplina Relação Água/Solo/Planta/Atmosfera, do Programa de PósGraduação em Ciência do Solo da Universidade Federal do Paraná, busca novos caminhos que demonstrem aos seus participantes, formas mais holísticas e sistêmicas de abordar ecossistemas, evidenciando a complexidade das infinitas relações presentes, levando-os a perceber, respeitar e compreender de forma integrada questões complexas como: a água na atmosfera, no solo e na planta, a dinâmica de nutrientes nos ecossistemas, a degradação do solo, entre outros. A questão de difícil resposta é: como proporcionar aos participantes da disciplina a compreensão de que os tópicos, extremamente técnicos, estão intrinsecamente ligados uns aos outros? E que, além de ligados uns aos outros, podem estar ligados a outros fatores que desconhecemos? Ou seja, como demonstrar que tudo está ligado, tudo se relaciona?

O principal objetivo deste ensaio é compartilhar com os leitores as dificuldades e os caminhos percorridos na utilização de um novo paradigma para o ensino-aprendizagem das diversas relações naturais existentes dentro de ecossistemas. Espera-se que este trabalho ajude na realização de reflexões e questionamentos, para que se possa consolidar uma nova maneira de abordar o meio ambiente dentro de programas de pós-graduação, onde são formados os futuros pesquisadores e professores que multiplicarão os seus paradigmas.

\section{Paradigma Cartesiano da Ciência}

A base da ciência moderna tem sua origem metodológica nas quatro regras propostas por René Descartes em 1637, que propôs separar o sujeito pensante (ego cogitans) e a coisa extensa (res 
extensa), isto é, separar a filosofia da ciência, colocando como expressão da verdade as idéias "claras e distintas". A segunda regra proposta por Descartes preconiza a divisão de cada problema encontrado em tantas pequenas partes quanto fosse possível e necessário para melhor resolvê-lo, isto é a redução do todo a suas partes, como postura metodológica, sendo esta, uma das mais caras tradições do pensamento científico atual (DESCARTES, 2002).

Nossa formação educacional, tanto na escola quanto na universidade, nos ensina a separar as disciplinas uma das outras para não ter que relacionálas, separando o objeto do seu contexto. Esta separação e fragmentação do saber é incapaz de compreender a complexidade da vida.

Corroboramos a visão de Almeida e Carvalho (2002) quando afirmam que a tradição do pensamento, que forma o ideário de nosso sistema de ensino, ordena que se reduza o complexo ao simples, que se separe o que esta ligado, que se unifique o que é múltiplo, que se elimine tudo que traz desordens ou contradições para o nosso entendimento. A inteligência, que só sabe separar, rompe o caráter complexo do mundo em fragmentos desunidos, fraciona os problemas e unidimensionaliza o multidimensional. E, mesmo quando tenta reuni-los novamente deixa lacunas enormes.

Isto pode ser verificado, por exemplo, ao estudarmos um ecossistema. Na química aprendemos que este é composto por carbono e nitrogênio e mais alguns elementos, que se ligam e desligam incessantemente, e que estes átomos participam de ciclos como os do nitrogênio, do fósforo, do potássio, da água, do carbono, mas pouco se sabe do ciclo do magnésio, constituinte da estrutura elementar para a realização da fotossíntese, fonte de toda a vida. Para a biologia os constituintes vivos do ecossistema são amontoados de células especializadas, que devido à configuração do código genético, nascem, se diferenciam e morrem, mas também pouco se sabe como milhões de microorganismos diferentes convivem e se relacionam em cada centímetro quadrado de solo. Para a física o ecossistema pode ser compreendido pelo fluxo de energia e suas relações tróficas. Para a economia um ecossistema é considerado como um provedor de recursos naturais tangíveis, necessários para a sobrevivência da espécie humana. Além destes aspectos que a importância cultural e social de um ecossistema é diferente para quem mora na cidade e para quem mora no campo.

$\mathrm{Na}$ verdade um ecossistema é tudo isto e muito mais, ele é, ao mesmo tempo, provedor dos insumos que proporcionam a nossa existência, e também o lugar onde habitamos. Como pode então ser possível entender um ecossistema analisando separadamente suas partes, se ele é composto por um número infinito de partes, que estão em dimensões diferentes, que mudam e se modificam a cada segundo e que possuem uma percepção diferente por cada pessoa?

Kuhn (2003) cunhou o termo "paradigma científico" para definir o universo de valores culturais ideológicos, históricos e epistemológicos que condicionam a produção do conhecimento. Em muitos de nossos cursos de Pós-Graduação impera o paradigma cientifico proposto por Descartes, edificado há mais de 350 anos, e que, em muitos aspectos permitiu a melhoria da qualidade de vida da humanidade. Porém é necessário atentar para suas conseqüências nocivas, que começam a se revelar, de forma contundente, no século XX e tem se acentuado no século XXI.

Precisamos de um novo paradigma, que seja uma evolução do antigo e desta forma possa auxiliar no desenvolvimento de novas propostas que sejam mais abertas, racionais, críticas, reflexivas, autocríticas, sustentáveis e aptas a se auto-reformarem.

\section{Teoria da Complexidade: um novo paradigma para abordar ecossistemas}

A teoria da complexidade / pensamento complexo, eclode como este novo paradigma, que não é algo 
concreto ou palpável, não traz uma fórmula e muito menos propõe uma técnica. Fonte (2004) coloca que o pensamento complexo trata-se de um processo mental, um modo de pensar que nos leva a uma tomada de consciência e conseqüentemente a modos de ver e sentir diferentes.

A palavra Complexus, deriva do grego, e significa o que está tecido junto, deste modo, há complexidade quando elementos diferentes são inseparáveis constitutivos do todo. A complexidade é o tecido de acontecimentos, ações, interações, retroações, determinações, acasos que constituem o nosso mundo (MORIN, 2001c). O pensamento complexo tenta dar conta daquilo que o pensamento simplificador desfaz ou é incapaz de compreender. De uma maneira geral, trata da conciliação das várias esferas do conhecimento, articula o que está dissociado e distinto; e distingue o que está indissociado (FONTE, 2004).

A teoria da complexidade nos alerta que se devem levar em consideração todos os diversos fatores que possuem alguma relação com o objeto que está sendo abordado, pois somente assim é possível entender de forma mais completa e correta a sua importância. Devemos ter coragem para enfrentar a confusão, a solidariedade dos fenômenos, a incerteza, a contradição.

Morin (2001a) nos ensina que o conhecimento não é um espelho das coisas ou do mundo, e sim somente uma tradução e reconstrução cerebral com base nos estímulos ou sinais captados pelos sentidos. Deste modo, devemos sempre questionar a atitude humana que acata paradigmas sem questioná-los.

A teoria da complexidade não deve ser considerada como uma receita ou uma resposta, mas sim uma motivação para pensar, ela afirma que é impossível conhecer o todo sem conhecer as partes, tampouco não se conhece as partes se não conhecer o todo (PASCAL apud. MORIN, 2001c). Acreditase que a complexidade deve ser um substituto eficaz da simplificação, permitindo a programação e o esclarecimento dos problemas da humanidade (MORIN, 2001a).
Morin (2001c) propõe que para a realização de estudos que utilizem a teoria da complexidade como um novo paradigma científico, se faz necessário evidenciar algumas dimensões que possam gerar informações e soluções mais próximas da realidade e que possuam veracidade, coerência e maior sustentabilidade, tais como:

a) Compreender o contexto - $\mathrm{O}$ conhecimento das informações ou dos dados isolados é insuficiente para a compreensão da realidade É preponderante situar as informações e dados em seu contexto para que eles ganhem significado e acrescentem conhecimento.

b) Entender as relações globais (entre o todo e as partes) - A dimensão global é maior que a contextual, ela é composta pelo conjunto das diversas partes ligadas a ele de modo interretroativo ou organizacional. É como a comunidade em que vivemos, que ao mesmo tempo em que nos modela também é modelada por nós. $\mathrm{O}$ todo tem qualidades ou propriedades que não são encontradas nas partes se estas estiverem isoladas umas das outras. Ao mesmo tempo certas propriedades podem ser inibidas pelas restrições provenientes do todo.

c) Ter uma abordagem multidimensional. Unidades complexas como o ser humano, a natureza ou a sociedade são multidimensionais: desta forma o ser humano é ao mesmo tempo biológico, psíquico, social, afetivo e racional. E estas dimensões se inter-relacionam permanentemente modificandose constantemente.

d) Entender a complexidade, onde todos os fatores constituintes e constituídos pelo estudo possuem grande relevância, influenciando de maneira significativa o seu sucesso ou fracasso no longo prazo.

Outro ponto preconizado pela teoria da complexidade é que a incerteza faz parte do mundo, e nós devemos considerar esta realidade. Nos séculos precedentes sempre se acreditou em um futuro que fosse repetitivo ou progressivo. A teoria da 
complexidade coloca que o futuro permanece aberto e imprevisível, por mais que tentemos controlar todas as variáveis, sempre existirá a possibilidade do incerto. Por exemplo, o tsunami que atingiu a Ásia no final de 2004, não foi previsto, bem como a seca que causou o desaparecimento de diversos lagos e rios da Amazônia em 2005. O incerto está presente em nossas vidas a todo o momento e temos que ter consciência disto, pois graças ao que não pode ser previsto é que surge o novo. Na visão da complexidade, o universo é o jogo e o risco da dialógica entre a ordem, a desordem e a organização. (MORIN, 2001c)

Por fim, evidencia-se, que todo conhecimento precisa ser contextualizado, multidimencionalizado, complexado, globalizado, pois somente assim ele será eficaz e útil; e não como atualmente, quando os conhecimentos gerados se encontram fragmentados em diversas disciplinas e muitas vezes escondidos atrás de estantes, praticamente sem função (MORIN, 2001c)

\section{A Abordagem Pedagógica para a Compreensão da Realidade}

As relações entre água/solo/planta/atmosfera não são possíveis de ser compreendidas em sua totalidade utilizando-se como base epistemológica o reducionismo proposto por Descartes, pois se fragmentarmos o todo para entender cada uma de suas partes, ao rejuntar estes fragmentos não encontraremos o mesmo todo, e sim somente um porção de cacos que não conseguem se encaixar devido a suas arestas. Isto acontece porque as relações presentes dentro de ecossistemas são dinâmicas, auto-reguladoras, complexas, incertas (CAPRA, 1998; ODUM, 1998).

Então surge a questão, que já foi abordada na introdução deste artigo. Como capacitar discentes, de um programa de pós-graduação, para a compreensão, com a máxima fidedignidade possível, do funcionamento de ecossistemas, que são múltiplos e de natureza complexa, isto é, derivado de um número indefinido de interações?
Fica evidente que esta não é uma tarefa fácil, e que não existe uma resposta pronta. Será descrito, de forma sucinta, o caminho que foi percorrido pelo grupo que participou da disciplina durante o segundo semestre de 2005, no estudo de um ecossistema da Ilha do Mel.

Como ponto de partida, fez-se necessário distinguir método de metodologia para que fosse possível quebrar alguns paradigmas vigentes. Diversos autores e pesquisadores consideram método e metodologia como sinônimos, porém para execução deste processo de ensino-aprendizagem o método foi considerado "a atividade pensante e consciente do sujeito", o modo como o pesquisador observa o mundo ao seu redor; e metodologia como os caminhos que o pesquisador ira percorrer e as ferramentas que serão utilizadas, para conceber os objetivos propostos. (MORIN, 2001a)

O método, em que se baseou a disciplina, foi o proposto pela teoria da complexidade, que busca utilizar uma visão mais abrangente e holística, respeitando as variadas dimensões existentes em qualquer objeto de estudo, sempre visando destacar e entender as contradições existentes, e ao mesmo tempo manter um olhar integrador. Neste método se considera que um indefinido número de fatores pode influenciar o objeto de estudo e ao mesmo tempo são influenciados por este, sendo que em grande parte não são passíveis de ser controlados, isolados ou quantificados com precisão. Quando utilizamos este método, é considerado que cada observador possuirá uma interpretação diferente do mesmo fenômeno e que cada fenômeno é uma experiência única e dificilmente se repetirá de maneira igual e sim talvez semelhante, contrapondo o método cartesiano.

Para que os discentes compreendessem e introspectassem este método, foi realizada, durante o período de aulas presenciais, a leitura e discussão de textos escritos por autores que alertassem para esta nova maneira de abordar ecossistemas, principalmente textos do austríaco Capra (1998), que é doutor em física teórica e um dos grandes 
pensadores e ativistas que hoje trabalham por uma sociedade sustentável.

Ciente de que somente a discussão dentro da sala de aula não possibilita a consolidação da aprendizagem; como parte complementar foi utilizada uma metodologia, baseada na pesquisa etnográfica, que se preocupou com uma abordagem do ecossistema que fosse ao mesmo tempo sistêmica, holística e dialética, aqui denominada "vivência da natureza".

A "vivência da natureza" foi realizada por meio de visita a um ecossistema em particular da Ilha do Mel, cujo objetivo principal não foi a coleta de dados ou a interferência nos processos existentes. Trabalhou-se a percepção das diversas dimensões do ecossistema escolhido, bem como sua interrelação com outros ambientes e processos distanciados no tempo e no espaço.

Após e durante a visita, foram realizadas trocas das percepções de cada participante, onde se evidenciou que cada um observa a natureza de um determinado jeito, de ângulos diferentes e que apesar de diferentes todos representavam, à sua maneira, a realidade.

\section{Ilha do Mel como Campo de Estudo}

A escolha deste espaço geográfico não foi aleatória, pois foi considerado que, embora em qualquer tipo de ecossistema existam interações complexas, naquele, em especial, elas poderiam ser mais facilmente percebidas. A Ilha do Mel está localizada na entrada da baía de Paranaguá - PR, apresentando como ponto mais alto a cota de 147,73m do morro do Nhá Pina, e algumas outras elevações de geologia cristalina. O restante da área é formado por planícies de sedimentação de areia marinha, que ocorreu durante o período pleistocênico (120 000 anos a.p.) e holocênico (11000 anos a.p.) em função de alterações no nível do mar, atribuídos a variações climáticas (períodos glaciais e/ou inter-glaciais) e a processos tectônicos ao longo do tempo geológico pretérito. Essa informação nos dá a primeira evidência da inter-relação temporal do ecossistema selecionado para a vivência, mas é preciso ir além. A variação no nível do mar configurou situações chamadas de regressão e transgressão marinhas que resultaram na formação dos chamados cordões litorâneos, que nada mais são do que vestígios do alinhamento das antigas cristas das praias. São marcas deixadas na superfície pela mudança do nível do mar, sob a forma de montes de areia alongados com no máximo dois metros de altura (mas geralmente muito menos), e alinhados paralelamente à costa e que são perfeitamente visíveis nas fotografias aéreas. A presença dos cordões litorâneos, portanto, confere à Planície Litorânea, da qual a Ilha do Mel faz parte, um "micro-relevo" suficiente para, aliado à profundidade do lençol freático, determinar a classe de solo que se desenvolve a partir dos sedimentos arenosos. Nas superfícies mais rebaixadas entre os cordões, ou às vezes em superfícies rebaixadas mais amplas onde se formaram lagoas em função da forma como se deu o processo, ocorre o acúmulo de água, não esquecendo que o clima é denominado "tropical super-úmido". A temperatura média em todos os meses é superior a $18^{\circ} \mathrm{C}$, e não há estação seca, pois a precipitação média no mês mais seco é superior a $75 \mathrm{~mm}$, chegando a ser registrados até $3000 \mathrm{~mm}$ de precipitação anual (INSTITUTO, 1994).

A alta precipitação, aliada ao "micro-relevo" e ao lençol freático próximo à superfície, resulta em áreas alagadas permanentemente ou na maior parte do ano. Nessas áreas alagadas podem se formar os Espodossolos ou os Neossolos quartzarênicos hidromórficos ou os Organossolos. Na área escolhida para a "vivência da natureza", ocorre predominantemente o Organossolo, solo constituído por material orgânico com espessura mínima de 40 cm (EMPRESA, 1999). A gênese desse tipo de solo, portanto, além de estar relacionado com os outros processos já mencionados está estreitamente ligada e correlacionada também com a vegetação. Ou seja, os resíduos da vegetação são depositados sobre a superfície e, em função do excesso de água, o 
resultado é um acúmulo de matéria orgânica parcialmente decomposta que quando atinge a espessura de $40 \mathrm{~cm}$, passa a ser denominado de Organossolo. É claro que o solo por sua vez afeta a vegetação pois sobre os Organossolos (e os outros solos hidromórficos) se desenvolve a Floresta Ombrófila Densa das Terras Baixas caracterizada pelo predomínio de Callophyllum brasiliense (guanandí), formando um estrato arbóreo contínuo entre 20 e 25 metros de altura, acompanhada por outras espécies, entre as quais a Tabebuia cassinoides (caxeta) (RODERJAN et al., 1990). No ecossistema visitado estas duas espécies estão entre as principais representantes do estrato superior, juntamente com Marlierea reitzii, Myrcia racemosa, Myrcia insularis, Ocotea pulchella e Ocotea tristis (SILVA, 1998). A discussão do grupo, no entanto, concentrou-se nas espécies guanandi e caxeta, por apresentarem as maiores alturas e diâmetros e um tronco retilíneo, sendo portanto espécies inclusive com valor comercial, embora as madeiras possuam características muito distintas.

A descrição reducionista do solo da área, composto exclusivamente de, em média, $80 \mathrm{~cm}$ de matéria orgânica em diferentes estágios de decomposição, sobrejacente à areia marinha, fortemente ácido (MARTINS, 2005) e permanentemente alagado, inevitavelmente nos levaria à conclusão de que tal ambiente edáfico seria inadequado para a produção de biomassa, principalmente sob a ótica da fertilidade agrícola do solo. Que tipo de relações entre o solo, a água e a atmosfera, no espaço e no tempo, poderiam explicar a presença e o desenvolvimento daquela vegetação, sobre aquele solo, principalmente as duas espécies consideradas, com aquelas alturas (acima de 20m) e aqueles diâmetros (acima de $50 \mathrm{~cm}$ )? Isso sem desconsiderar o fato da probabilidade daquela vegetação não ser primária, já que a área é de relativamente fácil acesso e bastante próxima às cidades de Paranaguá e Guaraqueçaba, as mais antigas do estado. Isso significa dizer que em áreas intocadas, as alturas e diâmetros seriam provavelmente ainda maiores. Como tentar explicar tais relações, à luz do conhecimento científico fragmentado à nossa disposição atualmente?

Será que uma descrição reducionista do clima, da geologia, da geomorfologia e do solo da ilha consegue traduzir a realidade intrínseca da floresta em sua total amplitude e magnitude? Ao caminhar dentro da floresta, com certa dificuldade em função das áreas mais alagadas e da densidade e diversidade das espécies arbóreas, arbustivas, herbáceas e epífitas, encharcando os pés, ao tradar o solo, ao abraçar as árvores analisando de maneira holística e sistêmica todos os componentes, tivemos a percepção das diversas dimensões, explícitas e implícitas, ou seja daquilo que se enxerga quando se tem olhos para ver até o que não se vê em função da própria dimensão física, como por exemplo a atividade dos microorganismos e processos dentro de cada indivíduo e dentro da floresta representada pelas diversas formas da sua vegetação. E ainda assim não fomos capazes de perceber praticamente nada da fauna associada, a não ser alguns pássaros e os mosquitos, é claro!

Assim, temos a caracterização dos componentes do ambiente, tentamos fazer o entendimento dos seus processos e a interação destes para compreender e explicar o seu funcionamento. Mas na visão holística, que podemos definir como sendo aquela segundo a qual o ambiente é um todo indivisível, e que não pode ser explicado pelos seus distintos componentes (físico, biológico, químico, geológico ou geomorfológco), considerados separadamente, nos vemos diante do ainda assim inexplicável, ao arrostar o nosso espaço.

\section{Conclusão e perspectivas}

Bursztyn (2004) resume de maneira contundente a angústia que nós, participantes de programas de pós-graduação, estamos passando, quando diz: "A universidade está em crise... pois não consegue mais ser como vinha sendo e não consegue também se tornar outra coisa". 
Continuamos a seguir a receita que surgiu durante o Renascimento, onde a observação armada da natureza e a experimentação de hipóteses tornaramse o paradigma da nova ciência. Para Laplace a natureza poderia ser por completo reconhecida e reduzida a um sistema inteiramente objetivo e perfeitamente previsível. Este paradigma se opôs às bases puramente racionais que predominavam anteriormente, ou seja, à filosofia clássica (PEREIRA, 2004). O dualismo entre as abordagens filosófica e experimental chega aos dias de hoje na oposição entre as pesquisas qualitativas e quantitativas; entre ciências "soft" e "hard", entre visões humanistas e tecnicistas.

Fazem-se necessário a superação deste dualismo e a conformação de um novo paradigma científico que seja capaz de solucionar esta dicotomia em que de um lado estão os saberes desunidos, divididos e compartimentalizados e, de outro as realidades ou problemas cada vez mais globais, multidisciplinares, transversais, multidimensionais, transnacionais, planetários.

O mesmo Laplace quando estava vivendo seus últimos momentos na cama afirmou: "O conhecimento que temos das coisas é pequeno... quando comparado com a imensidão daquilo em que ainda somos ignorantes" (ANDREOTTI, 2005)

Corroboramos a visão de Heemann (2004) na qual o programa de Pós-Graduação pode ser o lócus para o pensamento crítico, para o comportamento inquiridor, não servindo somente para a "transmissão de soluções técnicas prontas ou para o oferecimento de resoluções rápidas", na qual é valorizada somente a aprendizagem de conteúdos.

É necessário que os participantes de programas de pós-graduação busquem um novo paradigma para abordar o mundo, que leve à compreensão do meio ambiente e ao desenvolvimento da sociedade nos seus mais amplos sentidos e que esta compreensão e desenvolvimento tragam resultados positivos para a sociedade local, regional, nacional e mundial; tanto no curto quanto no longo prazo.
O processo aqui denominado "vivência da natureza" destaca a reflexão e aprimoramento técnico, sendo um mecanismo capaz de promover e aprofundar o conhecimento sobre a realidade global vivenciada, fomentando a elaboração crítica.

A vivência também é importante para incentivar o pesquisador a observar, conhecer e participar; valorizar a troca de informações e experiências em plano coletivo e interdisciplinar, evitando assim reduções simplificadoras. Força o participante a confrontar seus conhecimentos teóricos com a realidade, de modo a elaborar uma prática sobre a qual terá a oportunidade constante de refletir e assim construir novos conhecimentos teóricos e empíricos, numa proposta crítica e transformadora da produção do conhecimento. A "vivenciar da natureza" se torna parte preponderante para o cumprimento dos objetivos deste projeto, pois, por meio de uma abordagem que possibilita a interação teoria-prática, fornece ao participante, subsídios para a construção de uma problematização interdisciplinar da realidade, levando este a compreender criticamente a realidade presente no ecossistema abordado.

\section{Referências}

ALMEIDA, M. C.; CARVALHO, E. A. (Org.). Educação e complexidade: os sete saberes e outros ensaios. São Paulo: Cortez, 2002.

ANDREOTTI, F. Laplace, Pierre Simon (1749-1827). Disponível em: <http://www.fem.unicamp.br/ em313/ paginas/person/laplace.htm>. Acesso em: 14 dez. 2005

ARANHA, M. L. A.; MARTINS, M. H. P. Filosofando: introdução à filosofia. 2. ed. São Paulo: Moderna, 1993.

BURSZTYN, M. Meio ambiente e interdisciplinaridade: desafios ao mundo acadêmico. Desenvolvimento e Meio Ambiente: Interdisciplinaridade, meio ambiente $\mathrm{e}$ desenvolvimento: desafios e avanços do ensino e da pesquisa. Curitiba, n.10, p.67-76, jul./dez. 2004.

CAPRA, F. A teia da vida: uma nova compreensão científica dos sistemas vivos. 3.ed. São Paulo: Cultrix, 1998.

DESCARTES, R. Discurso do método: para bem conduzir a própria razão e procurar a verdade nas ciências. São Paulo: Paulus, 2002. 
EMPRESA BRASILEIRA DE PESQUISA AGROPECUÁRIA - EMBRAPA. Sistema Brasileiro de Classificação de Solos. Rio de Janeiro: Embrapa Solos, 1999.

FONTE, N. N. A complexidade das plantas medicinais: algumas questões de sua produção e comercialização. 2004. Tese (Doutorado em Agronomia) - Universidade Federal do Paraná, Curitiba.

HEEMANN, A. Considerações sobre alguns obstáculos à interdisciplinaridade na Pós-Graduação. Desenvolvimento e Meio Ambiente: Interdisciplinaridade, meio ambiente e desenvolvimento: desafios e avanços do ensino e da pesquisa. Curitiba, n.10, p.47-52, jul./dez. 2004.

INSTITUTO AGRONÔMICO DO ESTADO DO PARANÁ - IAPAR. Cartas climáticas do Estado do Paraná 1994. Londrina: IAPAR, 1994. (IAPAR, Documento, 18).

KUHN, T. S. Estrutura das revoluções científicas. São Paulo: Perspectiva, 2003.

MARTINS, K. G. Deposição e decomposição de serapilheira em floresta ombrófila densa das terras baixas sobre solos hidromórficos na Estação Ecológica da Ilha do Mel-PR. Dissertação. 2005. (Mestrado em Agronomia). Universidade Federal do Paraná. Curitiba.
MORIN, E. Ciência com consciência. 5.ed. Rio de Janeiro: Bertrand Brasil, 2001a.

Intodução ao pensamento complexo. 3.ed. Lisboa: Instituto Piaget, 2001b.

Os sete saberes necessários à educação do futuro. 4.ed. Brasília: UNESCO, 2001c.

ODUM, E. P. Ecologia. Rio de Janeiro: Guanabara, 1998.

PEREIRA, J. C. R. Análise de dados qualitativos: estratégias metodológicas para ciências da saúde, humanas e sociais. 3.ed. São Paulo: Editora da Universidade de São Paulo, 2004.

RODERJAN, C. V.; GALVÃO, F.; KUNIYOSHI, Y. S.; HATSCHBACH, G. G. As unidades fitogeográficas do estado do Paraná. Ciência \& Ambiente, Santa Maria, v.1, n.1, jul., p.75-92, 1990.

SILVA, S. A. M. A vegetação da planície litorânea da Ilha do Mel, Paraná, Brasil: composição florística e principais aspectos estruturais. 1998. Tese (Doutorado em Biologia) - Universidade Estadual de Campinas, Campinas. 
